\title{
El relato de la prensa mirista durante la dictadura cívico-militar, 1973-1989
}

\author{
The narratives of the mirista press during the civic-military dictatorship, \\ 1973-1989
}

\author{
Robinson Silva Hidalgo*
}

Resumen: En este texto buscamos conocer los relatos elaborados por el MIR para constituir la idea y práctica de Resistencia, las que se manifestaron tras el golpe de estado de 1973, impulsadas por las estrategias políticas definidas por el MIR. Es así que indagamos en los medios clandestinos El Rebelde y Agencia Informativa de la Resistencia (AIR), fuentes que nos permiten acceder a dichos relatos, definiendo los elementos que constituyen la oposición radical al régimen dictatorial, particularmente veremos las características de la prensa clandestina y sus sujetos de referencia para aterrizar -finalmente- en el ciclo de protestas nacionales y el rol de la prensa mirista en ello.

Palabras clave: Resistencia, MIR, prensa, dictadura.

\begin{abstract}
In this text we seek to know the narratives elaborated by the MIR to constitute the idea and practice of Resistance, which manifested themselves after the coup d'etat of 1973, driven by the political strategies defined by the MIR. This is why we investigate in the clandestine media The Rebel and Resistance Information Agency (AIR), sources that allow us to access these stories, defining the elements that constitute the radical opposition to the dictatorial regime, particularly we will see the characteristics of the clandestine press and its subjects of reference to land - finally - in the cycle of national protests and the role of the mirista press in it.
\end{abstract}

Keywords: Resistance, MIR, press, dictatorship

* Chileno, Doctor en Historia, Universidad Austral de Chile-Valdivia. robinson.silva@ uach.cl 


\section{Introducción}

Si bien el debate en torno a la construcción política mirista en época dictatorial tiene, a día de hoy, un amplio desarrollo en la historiografía del tiempo presente, ${ }^{1}$ aún hay asuntos que permanecen sin mayor reflexión. Uno de esos elementos guarda relación con el rol de los medios de prensa clandestinos que colaboraron en el trabajo político de construcción y fortalecimiento de la Resistencia interna a la dictadura, trabajo en el que las estructuras miristas tuvieron un rol relevante, por lo menos hasta entrada la década de los ochenta, y como en lo referido a la reconstrucción orgánica del proyecto político de esta organización. $^{2}$

Entonces, puesto que nuestro interés radica en el desarrollo del trabajo de los órganos de difusión resistentes, hemos elegido analizar la Agencia Informativa de la Resistencia (AIR) y El Rebelde para adentrarnos en este asunto. Primeramente, nos centraremos en los relatos que elabora la organización política, ello para conocer las ideas y prácticas que definieron el concepto de Resistencia que se quiso constituir en el Chile dictatorial y que son relatados por estos dos medios. Para llegar a una definición propia, es necesario realizar una contrastación crítica entre el discurso político que el MIR emite para desarrollar esa Resistencia en el país y, por otra parte, el relato de la prensa mirista que, además, se alimenta de dos códigos: el documento partidario y la información propiamente periodística; es en ese diálogo -declaración política e información de prensa-, donde esperamos encontrar qué se dijo y para qué se dijo y con ello acercarnos a la idea de Resistencia que se elaboró por parte del proyecto político mirista.

En un segundo apartado, nos interesa concentrar el análisis en cuestiones relativas a los medios propiamente estudiados, es decir, indagaremos en los contenidos que se

\footnotetext{
${ }^{1}$ La mayor parte de la historiografía acerca del MIR aborda los años de inicio y desarrollo de este movimiento-partido, estudiando su etapa más relevante en el contexto político chileno, no obstante, hay trabajos que nos adentran en los años de la Resistencia mirista a la dictadura. Trabajos desde la óptica del fracaso o declive de la organización como el de Osvaldo Torres Democracia y lucha armada. MIR y MLNTupamaros, Santiago, Pehuén, 2012; evaluaciones críticas están en Carlos Sandoval Movimiento de Izquierda Revolucionaria, coyunturas y vivencias, 1973-1980, Concepción, Escaparate, 2011; estudios específicos sobre la Resistencia hay en José Palma El MIR y su opción por la guerra popular. Estrategia político-militar y experiencia militante 1982-1990, Concepción, Escaparate, 2012; Eduardo Arancibia Las milicias de la Resistencia Popular, el MIR y la lucha social armada en dictadura, 1979-1984, Concepción, Escaparate, 2015 y Robinson Silva Resistentes y clandestinos. La violencia política del MIR en la dictadura profunda, Concepción, Escaparate, 2011. Uno de los trabajos más significativos referidos al grupo partidario es el de Igor Goicovic Trabajadores al poder. El Movimiento de Izquierda Revolucionaria (MIR) y el proyecto revolucionario en Chile, 1965-1994, Concepción, Escaparate, 2016.

${ }^{2}$ La bibliografía reciente comienza a dotarnos de estudios que nos ayudan a relevar el rol de la Resistencia en la definición del MIR post golpe, desde la mirada de la memoria militante mencionamos algunos textos destacados Mario Amorós, La memoria Rebelde. Testimonios sobre el exterminio del MIR de Pisagua a Malloco, 1973-1975, Concepción, Escaparate, 2007; Tamara Vidaurrázaga, Mujeres en rojo y negro. Reconstrucción de la memoria de tres mujeres miristas, 1971-1990, Concepción, Escaparate, 2006; Patricio Rivas, Chile, un largo septiembre, Santiago, LOM, 2007; Sergio Salinas, Memorias de militancia en el MIR, Santiago, RIL, 2014
} 
informaron, las maneras y mecanismos de resistencia que se relataron en estos textos periodísticos clandestinos, valorando con mayor atención la noticia relativa a la Resistencia en sus aspectos más concretos, desmenuzando el tipo de información que desarrollan ambos medios y, especialmente, buscando relevar los sujetos en cuanto productores de discursos y prácticas de esa actividad resistente y que se destacan como parte de la carne que resistió a la dictadura, sin dejar de considerar las transformaciones de esos mismos sujetos en el transcurso del gobierno de facto.

Finalmente, y en un tercer momento -como es conocido-, hacia los años ochenta es bastante más evidente que la Resistencia se desarrolló con inusitada fuerza, llegando a participar del ciclo de protestas nacionales que desestabilizan al régimen, ${ }^{3}$ de ello la prensa mirista informa y nos entrega: primero, la mirada acerca del desarrollo del proceso político $\mathrm{y}$, por otra parte, los cambios y continuidades en el relato que establece desde el comienzo del periodo dictatorial.

Metodológicamente, la prensa mirista a la que aludimos se constituye, para este caso, en dos boletines, en primer lugar, El Rebelde, medio nacido antes del golpe de estado y que se creó como el órgano oficial del partido cuando este ya alcanzó su consolidación a fines de los años sesenta. ${ }^{4}$ Este medio tuvo la característica de periódico mensual que asumió la voz del MIR respecto al debate político chileno en los gobiernos democristiano y de la Unidad Popular. Tras el golpe de estado continuó teniendo ese rol, aunque el contexto de clandestinidad atentó contra su masividad.

Por otra parte, la Agencia Informativa de la Resistencia (AIR) nace en el contexto dictatorial para hacer frente a la difusión de las acciones resistentes. La figura de Agencia vino a definir un trabajo formal de recabar información dispersa, tanto territorial como socialmente, que buscaba expresión, ello para argumentar que la Resistencia actuaba y crecía en la medida que el régimen dictatorial se perpetuaba y acumulaba resquemores y malestares en las clases populares chilenas. ${ }^{5}$

Además, la AIR, nacida en plena dictadura, es en sí misma la demostración de los avances orgánicos de la Resistencia que, pese a los duros golpes recibidos por la contrainsurgencia, en su tercer aniversario señalaba:

En 1980 un grupo de mujeres y hombres democráticos de la Resistencia Popular dieron vida a la AIR. Lo hicieron con esfuerzo con modestia, con esmero y con una clara visión política e ideológica de la tarea, ya que la Agencia constituye desde entones un eficaz

\footnotetext{
${ }^{3}$ Entre los textos fundamentales para conocer los elementos centrales de las Jornadas de Protesta nacional están Gonzalo De La Maza y Mario Garcés, La explosión de las mayorías. Protesta nacional 1983-1984, Santiago de Chile, ECO, 1985; Salazar Gabriel, Violencia política popular en las "grandes alamedas", Vol. I, Santiago de Chile, LOM, 2006; Eduardo Valenzuela, La rebelión de los jóvenes, Un estudio sobre anomia social, Santiago de Chile, Sur, 1984; José Weinstein, Los jóvenes pobladores en las protestas nacionales (1983-1984), Santiago de Chile, CIDE, 1989; Patricio Quiroga, "Las jornadas de protesta nacional: Historia, estrategias y resultados", Encuentro XXI 11, 1998, 42-60 y Antonia Garcés, "Los rostros de la protesta. Actores sociales y políticos de las jornadas de protesta contra la dictadura militar (1983-1986)", USACH, Santiago de Chile, 2011.

${ }^{4}$ Salinas, Op. Cit, 100-103.

${ }^{5}$ Salinas, Op. Cit,; Silva, Op. Cit, 82-83.
} 
instrumento al servicio del pueblo chileno. Hoy, en 1983, la AIR es ya un medio de comunicación social de la Resistencia consolidado. ${ }^{6}$ Había, entonces, que contar las acciones de la Resistencia.

\section{La necesidad de contar la Resistencia}

Iniciada la dictadura y de buen principio, el MIR se abocó a la tarea de entender qué sucedía en el nuevo período que se abría, el partido hizo importantes reflexiones, en medio de la persecución de sus militantes, para abordar de la mejor manera la nueva etapa. Es así que la necesidad de constituir un frente de Resistencia apareció como un elemento esencial. No podemos entender el carácter del MIR sin esta viga maestra de la acción política revolucionaria en los años post golpe de estado.

La constitución de la política resistente comenzó, eso sí, en medio de una polémica que se fue ampliando con el paso de los años posteriores a la asonada golpista. La cuestión del asilo se presentó como una disyuntiva que, como se ha conocido posteriormente, devino en la sobrevivencia de numerosos militantes, cuestión que no se vio así en un primer momento.

Es por ello que una de las marcas indelebles del mirismo tuvo que ver con las consecuencias en relación a la consigna, de por si compleja de asimilar: "el MIR no se asila", con esa frase se quiso refrendar el espíritu de lucha contra una dictadura que el mismo partido venía insistiendo que se produciría tarde o temprano. Es más, Miguel Enríquez, ${ }^{7}$ a la sazón Secretario General del MIR, expresó su rechazo a la salida masiva de militantes de la siguiente manera.

Llamar al exilio masivo de los cuadros es llamar a la disolución del partido, es llamar a esperar pasivamente, bajo añejas concepciones deterministas, que la situación se modifique espontáneamente...Así como existen experiencias positivas que corroboran nuestra opinión, hay otras donde se impuso al exilio masivo de los revolucionarios y, guardando las diferencias, no son para nada alentadoras: España, Brasil, Indonesia, etc... ${ }^{8}$

Es así que cabe preguntarse, a la luz de los hechos del terrorismo de estado que persiguió decididamente al MIR en los primeros años de la dictadura, cómo se produjo la gestación de esa Resistencia que, se señaló, se debía implementar una vez asestado el golpe contra la institucionalidad vigente. Ahora bien, hasta ahora se ha señalado que esa

\footnotetext{
${ }^{6}$ AIR, abril de $98,9-10$.

${ }^{7}$ Miguel Enríquez fue asesinado en la comuna santiaguina de San Miguel el 5 de octubre de 1974, producto de un enfrentamiento entre un grupo de miristas y un fuerte contingente militar y policial. Este golpe deja sin su máximo dirigente al mirismo, además de desmoralizar a los cuadros activos en la Resistencia. Un texto fundamental al respecto es el de Carmen Castillo Un día de octubre en Santiago, Santiago, LOM, 2013.

${ }^{8}$ Sin autor. Miguel Enríquez, Con vista a la esperanza, Santiago, Escaparate, 1998, 393. La cita está en el documento "Respuesta a un documento emitido por un grupo de compañeros de la colonia Valparaíso" y en este punto se repasan las diversas experiencias históricas que a junio de Miguel Enríquez hacían desaconsejable el exilio masivo de militantes, arguyendo los casos chino, vietnamita, camboyano y ruso como argumentos a favor de la permanencia de los cuadros para la construcción de las tareas de la Resistencia.
} 
Resistencia fue si no poca, inexistente y sobre esta línea de trabajo queremos definir el propósito del presente texto, puesto que la prensa mirista, de carácter clandestina, nos abre algunas posibilidades para conocer qué tan real es aquello. Es en esa idea que cuestiones como la prensa y la propaganda se constituyen como piezas fundamentales del desarrollo de la política mirista de Resistencia en el período dictatorial, el documento más relevante de ese momento señala, en referencia a las tareas inmediatas, lo siguiente.

La propaganda revolucionaria tendrá que adoptar nuevas formas que la limitarán necesariamente en su eficiencia. El peso específico de la agitación verbal e individual aumenta. Si bien la propaganda como forma de devolver confianza y esperanza a las masas y de darles conducción será fundamental su realización contemplará riesgos que deben ser disminuidos a través de la adopción de formas y técnicas que habrán de ser planificadas y preparadas rigurosa y minuciosamente por las direcciones de estructuras ${ }^{9}$.

De esta forma, ya en diciembre de 1973 la Comisión política del MIR tenía claridad de los desafíos en relación al carácter clandestino del trabajo propagandístico que debía desarrollar la organización, se era consciente de la poca eficiencia de los medios en el contexto de ocultamiento, así como de la necesaria planificación exhaustiva, en términos de la seguridad y desarrollo, de formas creativas de producción y distribución de los medios de prensa, que en nuestro caso visualizamos como los elementos propagandísticos de los cuales se habla, entendiendo que pudieron existir otros.

Ambos medios de carácter clandestino cumplían funciones diferentes y a través de su lectura podemos acercarnos mejor a la mirada mirista acerca de la situación política y social chilena de ese momento, realidad de la que estos medios formaron parte. Complementando sus relatos hay un explícito deseo de intervenir en el debate, por lo demás vedado para la izquierda revolucionaria.

Ahora bien, la necesidad de reorganizar los medios informativos y de propaganda llevó a considerar estas tareas en el marco de la construcción de la política resistente, dotándolas de una misión específica que constituyó su identidad desde este momento y hasta bien entrada la dictadura. Pero para comprender aquello y, en primer lugar, resulta necesario centrarse en qué se entendió por Resistencia para el MIR al despuntar el horror dictatorial.

La tarea más urgente de la lucha revolucionaria en Chile es organizar a los sectores de vanguardia y avanzados de la clase obrera y el pueblo, en Comités de Resistencia; impulsar a través de estos, la propaganda y agitación masiva; iniciar la resistencia activa; comenzar la guerra de desgaste contra la dictadura y el gran capital, que incluya formas de sabotaje... ${ }^{10}$

\footnotetext{
${ }^{9}$ Sin autor. Op. Cit. "La táctica del MIR en el actual período", 328.

${ }^{10}$ Rafael Agacino, Rodolfo Flores, Ricardo Frodden y Pedro Landsberger (Comp.), Táctica y acción política. Documentos MIR, 1965-1974, Concepción, Escaparate, 2016, 433. Específicamente se cita una entrevista a Miguel Enríquez en El Rebelde N $^{\circ} 99$ de agosto de 1974 aparecida como "A convertir el odio e indignación en organización de la Resistencia”.
} 
De estas declaraciones y muchos otros documentos públicos e internos del MIR logramos comprender que la Resistencia tuvo un carácter totalmente pragmático, a través de ella se buscó la reorganización del partido y la reconexión con las masas, el fín político dado a este trabajo refiere a la necesidad de activar los cuadros que, habiendo escapado de la represión, podían realizar estas tareas concretas, entre las cuales estaba la generación de órganos de prensa militante para fortalecer las tareas de la propaganda.

En particular, los sujetos a los que se refiere la práctica resistente son de vital importancia, en un primer momento se alude a "los pobres del campo y la ciudad" como los constructores de las acciones de rechazo al régimen, estos referentes sociales se van a ir ampliando y diferenciando en la medida que la dictadura perdure, la prensa en esto nos da señales más que claras, los sujetos que constituyen el trabajo de la Resistencia fueron mujeres, activistas de derechos humanos, estudiantes y un diverso mundo de personas que son convocados desde las páginas de los medios clandestinos, tal como veremos más adelante.

En esta construcción de Resistencia hay una polémica que se tomó las discusiones en relación a cómo viabilizar la Resistencia. En efecto, los debates en relación al asilo se trasuntan en la prensa mirista desde el primer día, haciendo referencia al ejemplo combativo de Miguel Enríquez, quien resiste al ataque de la represión, los cuadros miristas son impelidos a testimoniar su adhesión a la política de resistencia y negación al exilio. El Rebelde lo manifiesta así inmediatamente después de la muerte de Miguel Enríquez ejemplificándolo en la expulsión del militante Humberto Sotomayor

1.- Comunicamos a nuestros militantes y miembros, a las organizaciones hermanas $\mathrm{y}$ a todos los trabajadores que ha sido expulsado del MIR, Humberto Sotomayor, ex miembro de la CP (Comisión Política) por los cargos de deserción, cobardía y traición.

2.- El MIR es riguroso en la vigilancia del cumplimiento de las reglas partidarias y en la sanción de las faltas cometidas por sus miembros. Doblemente riguroso es en la sanción de sus dirigentes.

3.- El MIR decidió, el 11 de septiembre de 1973, permanecer en Chile, reorganizar el partido o impulsar la resistencia hasta el derrocamiento de la dictadura. El asilo es una forma de deserción. ${ }^{11}$

De esta forma, y desde el medio oficial del MIR, se da cuenta de la polémica más agria en los primeros años de clandestinidad y resistencia. En los años venideros esta disputa decaerá, puesto que fueron miles los cuadros del partido que partieron al exilio; desde el extranjero la cuestión no quedaría resuelta y en medio de esa diferencia es que se organizó la denominada Operación Retorno o Plan 78 destinado a retomar la línea de construcción resistente en el país.

Fue, sin lugar a dudas, un éxito de la política represiva de la dictadura el que se haya logrado exiliar a miles de miristas desde 1973, ello llevó a un fuerte cuestionamiento al interior del MIR y puso dudas sobre el éxito de la recomposición del partido. Lo anterior tuvo su corolario en el enfrentamiento, en una parcela de Malloco, en octubre de 1975,

${ }^{11}$ El Rebelde 102, diciembre de 1974, 8. 
entre los agentes de la DINA y el nuevo secretario general del MIR, Andrés Pascal Allende, acompañado de un grupo pequeño en el que se encontraban Nelson Gutiérrez y Dagoberto Pérez, dos importantes cuadros del partido. Pascal Allende y Gutiérrez lograron romper el cerco represivo y pidieron asilo, ello provocó una fuerte diferencia en el Comité Central del partido, considerando el trabajo pro resistencia que contemplaba el rechazo a la petición de asilo político. ${ }^{12}$

Pero la cuestión fundamental es que la Resistencia, pese a este primer traspié, logró recuperar la centralidad en el discurso de la prensa, la configuración de los órganos de difusión del MIR adoptó su razón de ser en cuanto la Resistencia se iba organizando y asestando los primeros golpes al aparato dictatorial, sucesivamente se van definiendo relatos en relación a formas de boicot y ataque al régimen que llenan las páginas de los medios clandestinos vinculados al MIR. Los números de El Rebelde que van entre 1975 y 1978 son elocuentes en el llamado a la construcción de la Resistencia, esos llamados se dirigen ahora fuera del partido, definiendo el carácter que debe tener, a juicio del MIR, la lucha contra la dictadura. ${ }^{13}$

En efecto, las interpelaciones de los editoriales de El Rebelde se dirigen a los partidos políticos y al sindicalismo. ${ }^{14}$ Estos llamados dan cuenta de una retórica urgente y dramática, pero también no dejan de animar a la constitución de las organizaciones resistentes. Esta ambivalencia define el carácter de los primeros años de la oposición radical al régimen. Podemos colegir, de la lectura de este medio, que la idea de Resistencia fue construyendo una entidad política en la medida del paso del tiempo, en ese transcurso fue sumando argumentos, dados por la lectura económica, social y política que se trasluce en los editoriales, pero también por nuevos fenómenos generados por el terrorismo de estado y las políticas refundacionales del capitalismo chileno, el incipiente modelo neoliberal.

\section{La prensa mirista en combate}

Efectivamente, los medios de prensa clandestinos constituidos en la lucha antidictatorial tienen un sentido en el marco de la construcción de la Resistencia, comenzaremos relevando algunas diferencias para asumir el análisis de cada uno en su justa dimensión.

En primer términos El Rebelde asumió el rol de órgano oficial del partido desde antes del golpe de estado, este papel asignado lo define como el medio con mayor carga editorial de la izquierda radical chilena; a través de sus páginas está la opinión del partido, se dicta la línea que los militantes miristas deben conocer y seguir. Si bien otros medios

\footnotetext{
12 Amorós, Op. Cit., 152-158.

${ }^{13}$ Es importante señalar que el editor de este medio, Ulises Gómez, sufrió detención y apremios en octubre del año 1979. Ascanio Cavallo, Manuel Salazar y Óscar Sepúlveda, La historia oculta del régimen militar, Chile 1973-1988, Santiago, Uqbar, 2008, 340.

${ }^{14}$ Las portadas de El Rebelde son explicitas en el mensaje, el $N^{\circ} 107$, de junio de 1975 señala: "A impulsar la Resistencia sindical!!!” y el N 128, de junio de 1977: “¡iA superar sectarismos para unir a la Izquierda!! A apoyar la lucha de los familiares de los 2500 desparecidos"
} 
también dan a conocer (previo al golpe) estas líneas políticas, durante la dictadura será este órgano quien tendrá que difundir las estrategias, decisiones y políticas que el partido define.

Lo anteriormente dicho y la férrea persecución al partido llevó a que El Rebelde fuera un medio que desarrolló poca información en términos de contenidos a inicios de la dictadura, cuestión que fue modificándose cuando esta publicación se afirmó, logrando continuidad en sus ediciones, mensuales por lo demás; hacia la década del ochenta va a contar con números más cuidados, que incorporaron fotografías e información de carácter nacional y regional, ello nos habla de una capacidad para recabar datos a través de redes que no son visibles en los primeros años de clandestinidad.

Por otra parte, la Agencia Informativa de la Resistencia (AIR) tiene una misión muy distinta, la de informar a la población en general de los avances organizativos y prácticos de la Resistencia en el país. Es por ello que el grueso es información dura, preferentemente acotada a las acciones de las milicias de resistencia, aunque no solamente. En la forma de un boletín, a veces de dos páginas y sin periodicidad más que la fecha en la que se encuentra publicada, este boletín es muy valioso a la hora de revisar el desarrollo de las políticas anunciadas en El Rebelde.

El combate de la prensa mirista se dirigió en concreto a sujetos sociales que se relevaron como sujetos en lucha contra la dictadura, es así que es de vital importancia reconocer el relato que se les dirigía para animarlos a participar de la lucha resistente. Abordaremos a manera de síntesis, quienes aparecen con mayor asiduidad en el relato: trabajadores, pobladores, mujeres, activistas de derechos humanos y estudiantes. Debemos señalar que, fuera de los activistas de derechos humanos, estos sujetos fueron los protagonistas del desarrollo social y político del MIR antes del golpe, por tanto, no es de extrañar que aparezcan como los actores convocados desde sus páginas y relatados cuando asumen ese rol resistente en la acción.

Antes de eso, y tal como se indica en la historiografía, la estrategia de Guerra Popular Prolongada implicaba el desarrollo de frentes de masas para la acumulación de fuerza social y, en el contexto dictatorial, también para las tareas propias de la lucha clandestina. ${ }^{15}$ Las páginas de El Rebelde y AIR manifestaron el desarrollo de estos frentes, devenidos en sujetos a los que se interpela para sumarse a la lucha resistente o para dar cuenta de los progresos que realizaron en el arduo camino para lograr el derrocamiento del régimen. Ahora bien, ¿quiénes fueron los sujetos sociales referidos en esa definición?

Ente los actores mayormente relevados en El Rebelde y la AIR, y como parte de las preocupaciones relevantes de estos medios, los asuntos relativos a los conflictos laborales son de los más llamativos y mayormente difundidos. Desde el principio de las actividades del medio en dictadura se definió esta línea, primero como llamado a la Resistencia desde los sindicatos o núcleos de trabajadores $\mathrm{y}$, posteriormente, en la cobertura de los distintos conflictos generados a partir de las reformas neoliberales implementados por el gobierno de facto.

Es una situación habitual en las páginas de El Rebelde informar de asambleas y huelgas que unen dos elementos, la reivindicación laboral y la represión política a las

${ }^{15}$ Palma, Op. Cit, 187-232. 
organizaciones de trabajadores. Respecto a situaciones de agresión en el sector cuprífero se informa:

El despido de cuatro dirigentes sindicales de Chuquicamata es la respuesta de la dictadura a los mineros por defender sus derechos y reivindicaciones, las bases sindicales de Chuquicamata, a pesar de los despidos, las amenazas, están decididos a seguir presionando para lograr imponer la negociación colectiva, mejorar su situación económica. Los mineros rechazan el plan Piñera. Los trabajadores de Chuquicamata, a pesar del estado de sitio de la presencia militar en el mineral, continúan reuniéndose y discutiendo el camino a seguir, y están dispuesto a dar la pelea, por eso CODELCO despidió a cuatro dirigentes con la intención de detener el conflicto que ve venir ${ }^{16}$

El periódico clandestino relata la dificultad de la organización sindical, siempre enfatizando que la intención de los trabajadores es hacia la lucha por la pervivencia de los sindicatos y las formas de lucha por las mejoras laborales. Como en este caso, son múltiples las informaciones de este tipo.

Pero los contenidos no se agotan en la esperable mirada sobre el desarrollo de las protestas en el mundo de los trabajadores. Este compromiso existió desde antes del golpe de estado, puesto que el MIR y sus órganos de difusión se disponían al debate ideológico desde el marxismo, relevando a los trabajadores como el sujeto constructor de la revolución socialista. Con el paso del tiempo vamos observando el desarrollo de los eventos de organización y acción movilizadora entre los pobladores. Desprendemos algunos de estos tópicos para dibujar el carácter de estos órganos de prensa clandestina.

En la quinta región, (Valparaíso) bajo la consigna “¡Por una Navidad digna para los hijos del pueblo, sin hambre, sin opresión!”, el Comité Pro Navidad realizó una campaña solidaria de recolección de cosas para la navidad de los hijos de los detenidos desaparecidos, presos políticos, trabajadores cesantes y del Plan del Empleo Mínimo y otros sectores empobrecidos de la población, en los locales del sindicato textil Viña y sindicatos de Artes Gráficas... En Santiago, el comité Pro-Navidad del Niño pobre y oprimido culminó una campaña de agitación y denuncia de la situación de hambre y opresión que vive la población, con un acto litúrgico-cultural efectuado en el campamento 22 de julio, el 24 de diciembre. ${ }^{17}$

La agitación en el mundo popular, en los barrios carenciados, fue de vital importancia para el desarrollo del movimiento anti dictatorial, como vemos en esta cita, los grupos activistas de la Resistencia vuelven a argumentar en relación a las dificultades socio-económicas y la represión, de la mano de aliados presentes en el espacio popular. Entre los más importantes estuvieron las comunidades cristianas que, tomando una fecha significativa en la cultura popular como la Navidad, la definen en el contexto del régimen, haciendo difusión de la necesidad de resistir a la dictadura.

${ }^{16}$ El Rebelde 146, febrero de 1978, 20. Recordar que el Plan Piñera hace referencia al nuevo código laboral implementado en 1978 y cuyo redactor fue el economista José Piñera.

${ }^{17}$ AIR, 1 de enero de $1981,2$. 
El MIR siempre tuvo un trabajo importante entre los campamentos y sectores carenciados de la población trabajadora fue, por tanto, una continuidad el trabajo de la Resistencia entre estos sectores de las grandes ciudades del país. Las informaciones de la prensa mirista son persistentes en los avances de la organización y lucha poblacional, la que se acrecentará una vez instaladas las Jornadas de Protesta Nacional a partir de 1983.

En todo ámbito de lucha resistente un elemento a destacar es la fuerte presencia de mujeres entre las activistas. Si bien la definición como sujeto social partícipe de la acción política no fue relevado desde buen principio por la organización partidaria, ni por ninguna otra de la izquierda chilena, su enorme entrega en los distintos frentes establecidos por la Resistencia fue haciendo que las mujeres conquistaran una presencia más que significativa en la lucha contra la dictadura.

La fecha más importante en el calendario de las luchas sociales para las mujeres, el día internacional de la mujer, 8 de marzo, fue siendo posicionado como el momento en que se visibiliza el rol de activistas de la Resistencia y portadoras de potenciales reivindicaciones en relación con el género. Uno de esos eventos, el de 1982 concretamente, está relatado en la AIR de la siguiente manera:

Para celebrar ese día, en Chillán se reunieron contingentes de mujeres en un acto en que se denunció la política destructiva que impone la dictadura y que afecta a las mujeres, y se difundió el Pliego de la Mujer que lanzó el CODEM, en sectores como La Feria, Pudahuel Norte, población La Victoria, entre otros, se efectuaron mitines (sic) y marchas relámpago, en que se llamó a las mujeres a reforzar su lucha antidictatorial y a unirse por conseguir derechos que el régimen no otorga. En La victoria las mujeres llevaban un lienzo que decía: "La mujer pobladora lucha contra el hambre y la opresión. ${ }^{18}$

Los hechos del 8 de marzo fueron creciendo en la medida que la dictadura transcurría y se perpetuaba, convirtiendo a esta fecha en un referente para los activistas de la Resistencia, si bien la mayor parte de la información respecto a las luchas feministas y del movimiento de mujeres se concentran en este momento, progresivamente se fue reconociendo el importante papel que tuvieron en la activación de la política resistente, incluyendo las acciones armadas de propaganda y las milicianas. ${ }^{19}$ Donde ese rol fue decisivamente importante fue en el mundo de la defensa de los derechos fundamentales.

El grupo de activistas y organizaciones vinculadas a la defensa de los derechos humanos creció debido a las circunstancias de la masiva violación de estos. Muchos familiares y profesionales de diversas áreas se sumaron activamente a esta actividad, es así que, sin considerarse un frente de masas, el relato de las publicaciones miristas asume y apela a este grupo. En 1977 se produjo la toma de la sede de Naciones Unidas en Santiago de Chile por parte de 26 activistas y familiares de detenidos desaparecidos para realizar una huelga de hambre y así presionar a la dictadura. El Rebelde refiere el hecho con una declaración del MIR para expresar lo siguiente

\footnotetext{
${ }^{18}$ AIR, abril de 1982, 4-5.

${ }^{19}$ Vidaurrázaga, Op. Cit, 49-330. El texto rescata la memoria de las milicianas en sus trayectorias como importantes constructoras de la Resistencia política.
} 
7.- Todo esto demuestra que solo la clase obrera y el pueblo, fortaleciendo la resistencia popular contra la dictadura, es el único camino para derrocar la dictadura, e implantar y ampliar los derechos humanos y libertados democráticas de nuestro pueblo. // La lucha de los familiares de los desaparecidos y la valerosa huelga de hambre llevada a cabo, demuestra cómo cada vez mayores sectores de nuestro pueblo desechan las ilusiones y la pasividad, y fortalecen el difícil pero único camino de la resistencia activa contra la dictadura. ${ }^{20}$

La definición fundamental tiene un punto de partida que debe anotarse correctamente, en la publicación las referencias a los héroes del partido, ejecutados y desaparecidos, son habituales. Cuando se señala que la lucha por los derechos humanos se engarza con la Resistencia se están tomando dos puntas del mismo hilo. Los familiares son también, en una parte importante, miembros activos o no de la estructura, o dialogan con ella. Es por ello que la lucha por los derechos humanos se encuentra definida como un elemento más del que se habla y al que se apela en el marco de construcción del relato resistente.

Por otra parte, un agente social históricamente asociado a las luchas sociales y políticas en Chile ha sido el estudiantado universitario. En múltiples ocasiones encontramos referencias a ellos en las diversas ediciones de la prensa clandestina vinculada al MIR y la Resistencia. Es así que los estudiantes fueron haciéndose parte de la movilización de manera creciente, primero en el marco de los conflictos propios de su actividad y del espacio en el que definen sus actividades. Espacio que también fue fuertemente reclamado como parte de la intervención dictatorial:

LA RESISTENCIA ESTUDIANTIL frente al clima de represión y terror desencadenado en las universidades, llegó a un punto culminante con la huelga de hambre en la Catedral Metropolitana de 9 estudiantes de la Academia de Estudios Pedagógicos (ex Instituto Pedagógico de la "U”) y de la Universidad de Santiago (ex UTE). Los huelguistas, que pertenecen a La agrupación de estudiantes sancionados y a la Unión de Estudiantes Democráticos (UNED), exigen la disolución de organismos de seguridad al interior de las universidades, la derogación de todas las órdenes de detención que pesan sobre los estudiantes, la creación de una nueva ley General de Universidades que sea plebiscitada por toda la comunidad universitaria y la formación de una comisión de latos nivel que elabore un estatuto de garantías sobre los derechos del estudiantado. ${ }^{21}$

Los estudiantes emplearon un repertorio similar a otros sectores represaliados por el régimen de facto, la huelga de hambre y los mítines protagonizados por universitarios son relatados de manera constante en El Rebelde y la AIR. Sumados desde temprano por el discurso resistente que surgía de las páginas de la prensa clandestina, al poco tiempo los observamos en otros frentes de la lucha de la Resistencia, en las poblaciones y el activismo feminista o de los derechos humanos, entre otros, mediante trabajos voluntarios o a través

${ }^{20}$ El Rebelde 128, junio de 1977, 27.

${ }^{21}$ El Rebelde 175, junio de 1981, 8-9. 
de sus militancias políticas, cuestión que se hará habitual durante el ciclo de protestas nacionales.

Llegados a este punto y en lo relativo a los sectores convocados a la lucha resistente, hay una evidente apuesta a la organización en torno a conflictos sociales, aunque siempre aludiendo a su identidad como sectores oprimidos, ofendidos por el régimen. No es menor entonces que estos sujetos hayan sido los protagonistas de la movilización general contra la dictadura a partir de 1983, convocados por el sindicalismo y agrupando a todos los demás, desembocando en la masiva participación de los pobladores y estudiantes como los agentes más numerosos en las protestas de los ochenta.

Los medios clandestinos fueron explícitos en expresar esas identidades colectivas como las constructoras de la Resistencia, en ello fueron abandonando la figura de los "frentes de masas" para relatar a los sujetos desde una tarea tan concreta como construir la oposición radical al régimen, utilizando el conflicto social provocado por la dictadura para reforzar la consciencia de clase y, con ello, la movilización política.

A continuación, ahondamos en algunos elementos de los mencionados en relación a las jornadas de protesta nacional, ello como corolario de la política resistente relatada por la prensa resistente, aunque en condiciones y contextos muy diferentes para la idea que el MIR pensó que desarrollaría. Este momento cúlmine de la lucha antidictatorial produjo el texto definitivo que El Rebelde y la AIR aportaron al debate político chileno.

\section{La prensa mirista en la protesta ochentera}

El ciclo de protestas de mediados de los ochenta es fundamental para entender el proceso político que llevó al cierre de la dictadura. ${ }^{22}$ Sin embargo, suele entenderse muy mal el rol que tuvo la Resistencia y su difícil camino en la constitución del movimiento opositor a la dictadura cívico-militar. Cuando el ciclo movilizador se inició, en mayo de 1983, los sectores más activos de la política resistente habían echado a andar con decisión, tal como El Rebelde y AIR nos muestran. La prensa clandestina fue vital en la visibilización de la denominada reanimación de la lucha, como lo definen estos medios. Como cuando se celebraron los tres años del CODEPU (Comité de defensa de los derechos del pueblo), organización creada por la izquierda radical para la defensa de los derechos humanos.

Sentados, de pie, en los palcos, en los pasillos, repletándolo todo con sus lienzos y gritos, obreros, pobladores, estudiantes, saludaron estos tres años de vida de la organización popular. Y en todo momento el saludo a las Milicias de la Resistencia. Entre un orador y el siguiente, antes o después de una canción, en medio de los aplausos para un artista popular de la danza o la poesía, el grito hacía derrumbar las paredes: “¡A crear, a crear, la Milicia Popular! $!^{23}$

\footnotetext{
${ }^{22}$ Robinson Silva, Resistencia política y origen del movimiento social anti dictatorial en Chile, 1973-1988, Tesis para optar al título de doctor en Historia, Universitat de Barcelona, 2014, 260-267.

${ }^{23}$ AIR, diciembre de 1983,2
} 
La prensa clandestina parte de la Resistencia entró en una nueva etapa, acompañada por la masiva protesta popular, en ese sentido también notamos cambios en algunos elementos del relato que entrega en sus páginas.

A través de la prensa mirista podemos acercarnos a otra mirada del proceso en los años ochenta. Tanto las organizaciones como acciones y generación de visiones políticas que se relatan en la prensa clandestina dan cuenta de otras formas de acción política y cómo los medios clandestinos las relevaron, ello en franca diferencia respecto a los medios de oposición moderada que comenzaron a circular en esta década. ${ }^{24}$

Una diferencia en este aspecto y tal vez motivada por esa época de convulsión en el espacio público, las formas del lenguaje se distanciaron del análisis político más formal de los primeros años. En una editorial se señala: "El Paro Nacional Obrero y Popular del 30 de octubre será una bofetada que el pueblo asestará con toda su fuerza en pleno hocico de la dictadura". ${ }^{25}$ Este lenguaje directo y claro ayuda a distanciarse de la prensa moderada de oposición, adoptando un estilo propio al medio, pero también diferente del que tuvo en los sesenta e inicios de los setenta. Por su parte, la AIR se plantea de la siguiente forma frente a la protesta:

La tarea para el 30 de octubre es una sola: no se trabaja, no hay clases, todo el comercio cierra sus puertas, no hay movilización colectiva; habrá caceroleo barricadas por miles, expropiación de alimentos para saciar el hambre, miguelitos, apagones, golpes a la represión criminal, en una palabra, el pueblo se tomará cada una de las comunas de Chile ${ }^{26}$

Es innegable que para los medios clandestinos hubo un interés especial en potenciar las formas de lucha popular callejera, los números tanto de El Rebelde, como de la AIR fueron explícitos en el llamado, incluso en la pedagogía de la protesta, muchos de sus números tuvieron manuales de como encender barricadas o fabricar bombas molotovs, también como protegerse de las detenciones o temas de seguridad en las manifestaciones públicas. Así, este ciclo de movilizaciones contó con la prensa resistente como un relator de sus avances y características más notables en las acciones que emprendió la lucha popular.

En este sentido, y de forma particular, las editoriales de El Rebelde nos ayudan a comprender el seguimiento y análisis que se realizó desde el medio respecto a las Jornadas de Protesta Nacional, en este sentido hubo una permanente evaluación de las acciones de protesta, refiriendo de manera explícita el avance de tales actividades y el daño que esto provocaba en la acción del oficialismo dictatorial, junto con ello se alude al mejoramiento de la práctica resistente en su logística y organización. ${ }^{27}$

\footnotetext{
${ }^{24}$ Nos referimos a las revistas Hoy, Análisis, Apsi y Cauce, entre las de mayor influencia y que son toleradas por el régimen a partir de 1977. http://www.memoriachilena.cl/602/w3-article-773.html

${ }^{25}$ El Rebelde, octubre de 1984, 2. Este número de 5 páginas es un especial dedicado a la preparación del Paro Nacional, denominado Hoja de Emergencia, se entregan análisis político, pero también la manera en que se debe preparar el combate callejero,

${ }^{26}$ AIR, octubre de 1984,2

${ }^{27}$ El Rebelde 194, 13. En esta edición se recuentan los apagones en cuatro regiones del país, además de los incidentes en las tres grandes urbes chilenas: Santiago, Valparaíso y Concepción, de esta manera se deja en evidencia la acción concertada para realzar la manifestación de protesta contra el régimen de facto.
} 
En mayo de 1983, al convocarse la primera gran protesta del ciclo, la editorial de $E l$ Rebelde manifestaba que: "El objetivo de derrocar a la dictadura es una tarea de definido carácter popular, democrático y revolucionario..." ${ }^{28}$ Desde el primer momento se declara la intención de participar activamente en la protesta y que sean las organizaciones populares quienes la conduzcan. Más adelante señala: "No es admisible que esos sectores vengan ahora a imponer "sus" condiciones al pueblo y que el eje de tales condiciones sea la exclusión de los partidos obreros, populares y revolucionarios del frente antidictatorial". ${ }^{29}$

Desde un comienzo, entonces, las diferencias con la oposición moderada se plasmaron en los medios clandestinos, pues sería este un tema de permanente discordia durante el ciclo de protestas. Cada convocatoria tuvo esta polémica como parte del debate $\mathrm{y}$, en particular, la prensa mirista tuvo una posición muy en contra del cariz que los partidos políticos de corte mesocrático quisieron imprimirle a la protesta.

Las evaluaciones respecto al debate que se planteó queda refrendado hacia 1986 , cuando el ciclo de protesta llegó a su fin, abriendo la negociación en medio del conflicto. El Rebelde lo definió de la siguiente manera:

Los personeros DC, de la socialdemocracia y de otros partidos que se dicen de oposición, están haciendo del "año decisivo" el año de la claudicación. Lo que se discute hoy es cuáles son los mejores instrumentos para garantizar el éxito de la negociación. Hay que lamentar que sectores y partidos de la Izquierda se estén subiendo al mismo carro. ${ }^{30}$

Por otra parte, los últimos años del ciclo de protestas hacen que la línea editorial de El Rebelde se dedique, de manera particular, a analizar la negociación sostenida por los agentes de la oposición moderada y la dictadura. El mensaje es permanente en relación establecer una clara diferencia en torno a mantener la línea de la insurrección callejera, a esas alturas abortada por la oposición negociadora.

La acción informativa de la AIR se desarrolló durante este período con un leve cambio en la manera de entregar la información, los recuentos habituales de acciones milicianas y actividades de la Resistencia, ahora se enmarcaron en las convocatorias a protestas nacionales. Sin lugar a duda, ello fue producto del recrudecimiento de este tipo de eventos en las fechas de ocurrencia de las manifestaciones.

Para el 11 de mayo la protesta abarcó gran parte del territorio. Hubo caceroleos, se enfatizó la acción directa contra la represión; actuaron, conduciendo la lucha en niveles superiores, múltiples brigadas milicianas; hubo barricadas y gran coordinación en la lucha; apagones en Santiago, Conce (Concepción), Valparaíso y otras ciudades; marchas, mitines estudiantes y profesionales, por los derechos humanos, etc. ${ }^{31}$

\footnotetext{
${ }^{28}$ El Rebelde, mayo de 1983, 1

${ }^{29}$ Ibid.

${ }^{30}$ El Rebelde 234, diciembre de 1986, 1

${ }^{31}$ AIR, junio de 1984,8
} 
Ahora bien, el medio entendió la necesidad de destacar las actividades de la protesta, subrayando que estas acrecentarían los efectos políticos de las manifestaciones y, por ende, el desarrollo de la Resistencia y su capacidad para derrocar la dictadura. En esa línea, el editorial de El Rebelde plantea que:

La superación de las debilidades y deficiencias en las organizaciones de masas, mejorando la coordinación local, regional y nacional de ellas, en particular la participación del movimiento sindical, es una tarea urgente. Se requieren centenares de brigadas y Milicias que actúen en estrecha concordancia con las movilizaciones populares". ${ }^{32}$

En definitiva, el ciclo de protestas de mediados de los ochenta definió claramente la proyección de la política resistente expresada en los medios de difusión clandestinos, eso sí, expresando una diferencia profunda con la oposición moderada que, a principios de la dictadura se pretendió atraer a los postulados de un frente muy amplio de lucha contra la instalación del gobierno militar de facto.

Cuando la dictadura se acercaba a su término administrativo, en 1988, El Rebelde continuaba desarrollando los argumentos en función de la dicotomía entre movilización y negociación, además de oponerse radicalmente al plebiscito y la apertura de los registros electorales para la inscripción masiva de los chilenos en la estructura jurídica diseñada por el régimen. Con ello apuesta por el rompimiento con todo aquello que signifique la participación en las reglas "democráticas" que la oposición moderada aceptó.

\section{Conclusiones}

Las publicaciones de El Rebelde y AIR representaron el registro fundamental del pensamiento de un sector perseguido y minorizado en el estrecho debate político de la época dictatorial. Desde la clandestinidad lograron plantear una lucha que, como se trasunta en sus páginas, logró posicionar una postura política acorde a la definición de Resistencia que encontramos en el primer planteamiento de Miguel Enríquez.

Si matizamos los alcances, podemos decir que hay aportes en estos medios desde la perspectiva de la definición de sujetos colectivos actuantes en la Resistencia y que este tipo de prensa releva claramente representados pues interesa destacarlos como los sujetos que definen de mejor forma la política resistente del MIR. Ello es un aporte a la lectura histórica del periodo dictatorial y nos acerca a una comprensión más acotada de los significados sociales de su política. Ahora bien, los asuntos atingentes a violaciones a los derechos fundamentales ocuparon una parte importante de las páginas de ambos medios y agruparon a otras identidades. Eso es un aspecto relevante en la lectura de la prensa clandestina estudiada y define un aspecto no contemplado en la definición original pensada por el partido. Fueron los hechos represivos quienes pusieron el tema de derechos humanos y sus activistas como protagonistas del relato resistente.

\footnotetext{
${ }^{32}$ El Rebelde, $\mathrm{N}^{\circ} 215$, noviembre de 1984, p. 2
} 
Por otra parte, la referencia permanente a los sujetos sociales actuantes en la Resistencia nunca sustituyó un elemento central en la elaboración del relato de El Rebelde, la lectura política del período en el que se situaba; del mismo modo, la AIR matizó en sus ediciones su labor eminentemente informativa con los debates que propuso el MIR en tanto organización política. En todo caso, ambos medios tuvieron una línea de permanente análisis de la situación política y social del país, desde la óptica resistente, relevando hechos que marcaban su rol de órganos difusores de aquella mirada. Es así que vemos la complementariedad entre ambos medios, cuestión que nos hace pensar en una estrategia pensada con cuidado. Ello merece un estudio en sí mismo desde la perspectiva de la historia política.

También cabe señalar las nuevas posibilidades que se abren para estudiar estas fuentes, partiendo por hacer análisis desde el enfoque de la teoría de la comunicación, así como generar nuevas preguntas a estos documentos. Para la historia social esto apuntaría a generar testimonios de los protagonistas para explorar preguntas relativas a la relación de los medios con las movilizaciones sociales, o la conexión de redactores y reporteros con los órganos políticos y cómo influyó en el trabajo realizado, entre múltiples cuestiones a explorar.

Finalmente, señalar que los aportes de la prensa clandestina colaboran para entrar con mayor profundidad en la comprensión de fenómenos políticos y sociales controversiales, en este caso, ya sea por la falta de debate crítico sobre los problemas de investigación referidos de la dictadura y la transición, pues abundan los relatos condescendientes emanados ya desde el aparato estatal o de la academia para explicar esos procesos. Por suerte estos textos siguen aquí para permitirnos nuevas miradas sobre el problema.

\section{Bibliografía}

\section{Prensa}

El Rebelde, 1974-1988, Fondo Documental Eugenio Ruiz-Tagle, FLACSO

Agencia Informativa de la Resistencia (AIR), 1980-1984, Fondo Documental Eugenio Ruiz-Tagle, FLACSO.

\section{Libros y Artículos}

Agacino, Rafael; Flores, Rodolfo; Frodden, Ricardo y Landsberger, Pedro (Comp.), Táctica y acción política. Documentos MIR, 1965-1974, Concepción, Escaparate, 2016.

Amorós, Mario, La memoria Rebelde. Testimonios sobre el exterminio del MIR de Pisagua a Malloco, 1973-1975, Concepción, Escaparate, 2007.

Arancibia, Eduardo, Las milicias de la Resistencia Popular, el MIR y la lucha social armada en dictadura, 1979-1984, Concepción, Escaparate, 2015.

Castillo, Carmen, Un día de octubre en Santiago, Santiago, LOM, 2013.

Cavallo, Ascanio; Salazar, Manuel y Sepúlveda, Óscar, La historia oculta del régimen militar, Chile 1973-1988, Santiago, Uqbar, 2008. 
De La Maza, Gonzalo; Garcés, Mario, La explosión de las mayorías. Protesta nacional 1983-1984, Santiago de Chile, ECO, 1985.

Goicovic, Igor, Trabajadores al poder. El Movimiento de Izquierda Revolucionaria (MIR) y el proyecto revolucionario en Chile, 1965-1994, Concepción, Escaparate, 2016.

Palma, José, El MIR y su opción por la guerra popular. Estrategia político-militar y experiencia militante 1982-1990, Concepción, Escaparate, 2012.

Quiroga, Patricio, "Las jornadas de protesta nacional: Historia, estrategias y resultados", Encuentro XXI, Santiago de Chile, Año 4 Nº 11, 1998, pp. 42-60.

Rivas, Patricio, Chile, un largo septiembre, Santiago, LOM, 2007.

Salinas, Sergio, Memorias de militancia en el MIR, Santiago, RIL, 2014.

Sandoval, Carlos, Movimiento de Izquierda Revolucionaria, coyunturas y vivencias, 19731980, Concepción, Escaparate, 2011.

Salazar, Gabriel, Violencia política popular en las "grandes alamedas", Vol. I, Santiago de Chile, LOM, 2006.

Silva, Robinson, Resistencia política y origen del movimiento social anti dictatorial en Chile, 1973-1988, Tesis para optar al título de doctor en Historia, Universitat de Barcelona, 2014.

Silva, Robinson, Resistentes y clandestinos. La violencia política del MIR en la dictadura profunda, Concepción, Escaparate, 2011.

Sin autor, Miguel Enríquez, Con vista a la esperanza, Santiago, Escaparate, 1998.

Torres, Osvaldo, Democracia y lucha armada. MIR y MLN-Tupamaros, Santiago, Pehuén, 2012.

Valenzuela, Eduardo, La rebelión de los jóvenes, Un estudio sobre anomia social, Santiago de Chile, Sur, 1984.

Vidaurrázaga, Tamara, Mujeres en rojo y negro. Reconstrucción de la memoria de tres mujeres miristas, 1971-1990, Concepción, Escaparate, 2006.

Weinstein, José, Los jóvenes pobladores en las protestas nacionales (1983-1984), Santiago de Chile, CIDE, 1989.

\section{Enlaces electrónicos}

Sin Autor, "Periodismo de oposición", http://www.memoriachilena.cl/602/w3-article773.html, Recuperado el 13 de julio de 2017. 